\title{
Effect of continuity of refinery on the working index of electric arc furnace
}

\author{
Iliyasu Kayode Okediran ${ }^{1}$, Musibaudeen Olatunde Idris ${ }^{1}$, Olayide Rasaq Adetunji ${ }^{2,}{ }^{*}$, Busayo Adeboye ${ }^{1}$ and \\ Abdulhafiz Ademola Adefajo ${ }^{1}$
}

${ }^{1}$ Mechanical Engineering Department, Osun state University, Osogbo, Osun State, Nigeria.

2 Mechanical Engineering Department, Federal University of Agriculture, Abeokuta, Nigeria.

Global Journal of Engineering and Technology Advances, 2021, 07(03), 001-007

Publication history: Received on 19 April 2021; revised on 25 May 2021; accepted on 28 May 2021

Article DOI: https://doi.org/10.30574/gjeta.2021.7.3.0072

\begin{abstract}
The need for metal usage is indispensable in the daily activities of human life. Metal is needed for the construction of different infrastructures such as houses, roads, bridges etc but despite the fact there is huge amount of metal available, it does not meet the global demand. Thus this paper investigated continuity of refinery as a measure to improve the efficiency of Electric Arc Furnace. In order to achieve maximum precision during production, getting the product at relatively reduced price has remained a major problem to Scientists. The experiment was conducted at industrial scale whereby the time was varied from 20 to 40 minutes while energy consumption rose from 0.0542 to $0.1103 \mathrm{~mW}$ Hour/ton and productivity fell from 253.0 to 99.2 ton/Hour. The data were collected from active furnace in Zerepaves Metallurgical plant, Russia and analyzed with software package for accuracy. It can be concluded that increasing refinery continuity reduces working productivity of the electric arc furnace.
\end{abstract}

Keywords: EAF; Steel; Efficiency; Productivity

\section{Introduction}

Total continuity of melting period can be defined not only by the time of its location under current in the furnace, but also time used on auxiliary technological operation, fulfilled while the furnace was switched off ordinarily on the onloading of second or the next budding scrap [1-3]. In metallurgical plant firm Vallurek in Anzene France already in 1972, judging by the result of self-chronometry, 60 ton EAF stopped on each pot 3-4 minutes. Continuity of smelting on that furnace was 2 hours in February 1984. Stop time of furnace on each pot in 100 ton furnace plant in Haisewide was averagely 3 minutes, and interval between smelting conducted with ruminants in the furnace 15-25 ton liquid steel 9.1 minutes. End of smelting here lasted for 3 minutes when total cycle of smelting 80.9 minutes. Interval pause when poring each of the pots by scrap was $3 \mathrm{mins} / 0.05 \mathrm{hour} /$ and became typical so also for other high productivity furnace can be explained by the fast mechanisms of mixing pots by over-heading cranes, electrodes $(0.35-0.75) \mathrm{kW}$-Hour electric energy [4-7]. Theoretically, by the total energy usage of arc, for that it is necessary $0.86 \mathrm{MJ} / \mathrm{T}^{0} \mathrm{C} / \mathrm{about} 0.24 \mathrm{KW}$ Hour $/ \mathrm{T}^{0} \mathrm{C} /$.

Judging by these data, in 100ton furnaces relative power $750 \mathrm{KV}$.A/ton and oxygen usage $1000 \mathrm{~m}^{3} / \mathrm{Hour}_{\text {when }} 100 \%$ of its assimilation, speed of heating metal in the melting oxidizing period of smelting while using high degree, secondary voltage can attain $(12-14)^{\circ} \mathrm{C} /$ minutes. By increasing temperature from 1550 to $1670^{\circ} \mathrm{C}$ and oxidizing $0.2 \%$ of carbon, as it is accepted in energy balance, continuity of melting period can be reduced to 9-10 min, in average up to 15-20 minutes, with consideration of stop-over to furnace to take the specimen of metal and its temperature record [1]. Metal is needed for the construction of different infrastructures such as houses, roads, bridges etc .but despite the fact there is huge

\footnotetext{
${ }^{*}$ Corresponding author: Olayide Rasaq Adetunji

Mechanical Engineering Department, Federal University of Agriculture, Abeokuta, Nigeria. 
amount of metal available, it does not meet the global demand. Thus this paper investigated continuity of refinery as a measure to improve the efficiency of Electric Arc Furnace.

\section{Methodology}

The experiment was conducted at industrial scale whereby the time was varied from 20 to 40 minutes while energy consumption rose from 0.0542 to $0.1103 \mathrm{~mW}$-Hour/ton and productivity fell from 253.0 to 99.2 ton/Hour .The data were collected from active furnace in Zerepaves Metallurgical plant, Russia and analyzed with software package for accuracy.

Table 1 Time for Furnace Operation.

\begin{tabular}{|l|l|l|}
\hline $\mathbf{S} / \mathbf{N}$ & Operation & Time(s) \\
\hline 1 & -Filling the furnace on-loading the first scrap, put on and charge of electrode & 20 \\
\hline 2 & - Melting the budding materials including internal operation pause & 55 \\
\hline 3 & -Oxidation period; Heating and de-carbonation of the metal & 15 \\
\hline 4 & -Delivery of metal from the furnace & 5 \\
\hline 5 & Total & 95 \\
\hline
\end{tabular}

This above continuity corresponds to the value of time of one smelting cycle/80-95minutes/; shown in the work on the basis of working index of high productive modern EAF/650-800kV.A/ton/, by authors of the furnaces of $3^{\text {rd }}$ generation.

Continuity of smelting cycle reduced even in subsequent years; in 1985, better results for furnaces capacities (100-120) ton closed to 70 minutes. Continuity reduced as a result of intensification of technological periods of smelting and organization of methods, directed to the reduction of delay caused by internal and inter-smelting breaks.

For cutting down the melting time of budding materials under current [2] nowadays, widely use addition of oxygen gas to the working plane of furnace, oxygen chamber, positioned in the wall of the furnace between electrodes and on the windows . Generally, use of oxygen rise to $30 \mathrm{~m}^{3} /$ ton, to be mentioned during the melting period up to (20-25) $\mathrm{m}^{3}$. Continuity of refinery is one of the basic variants of continuity of oxidizing period/ one slag process/, and was accepted to be equal to $20 \mathrm{~min}$. Value of temperature can be something else depending on the condition of the process.

Circumstances that have effects on the continuity of oxidizing period are as follows:

-Carbon content during melting,Content of phosphorus in the budding materials,Degree of alloying metal,Organization of holding the process.

Value of T defines the relative continuity of refinery

$\operatorname{tpa}_{\varphi}=\frac{T-t}{G \cdot 60 \cdot K \cdot P \cdot T}$. Hours $/$ ton

Where T- total continuity of process of refinery (minutes)

$t_{n k t}$-continuity of stopping the current for refining period (minutes)

G- Furnace capacity (ton)

$\mathrm{K}_{\mathrm{t} \text { cu- }}$ coefficient of throwing the current for oxidation period=1.09

By varying the T from 20-40 (minutes), we calculated /on the computer /electric and working characteristics according to methods used in [8-10]. Result of the calculation and optimization parameters of the refinery is as shown in the Table 2. and Figure 1. 


\section{Results}

The results obtained are presented in Tables 2 to 5 . Table 2 shows the effect of continuity on usage and productivity of electric arc furnace.

Table 2 Effect of continuity of refinery on usage of electric-energy and efficiency (productivity) of furnace for refinery period.

\begin{tabular}{|c|c|c|c|c|c|}
\hline T, minutes & $\mathrm{T}_{\text {tex, Hour/ton }}$ & $\mathrm{I}_{1}, \mathrm{~A}$ & $\mathrm{q}_{\text {ref, }, \text { ton/Hour }}$ & $\mathrm{T}$, Hour/ton & $\mathrm{W}_{\text {refmW-Hour/ton }}$ \\
\hline 20 & 0.00397 & 34934 & 253.0 & 0.00395 & 0.0542 \\
\hline 25 & 0.00527 & 33457 & 190.0 & 0.00526 & 0.0662 \\
\hline 35 & 0.00703 & 32293 & 142.5 & 0.00702 & 0.0823 \\
\hline 40 & 0.01009 & 31199 & 99.2 & 0.01008 & 0.1103 \\
\hline
\end{tabular}

If the line is straight, then of course we can say that relation between $\mathrm{x}$ and $\mathrm{y}$ is linear;

$\mathrm{Y}=\mathrm{AX}+\mathrm{B}$, where $\mathrm{A}$ and $\mathrm{B}$ are constants.

For non-linear dependent types of formula, we can define through compare of the drawn with the curves.

Analytic criteria exist for checkup of linear dependence between X and Y; by experimental data defined.

$\Delta \mathrm{Xi}=\mathrm{Xi}+1-\mathrm{Xi}: \Delta \mathrm{Yi}=\mathrm{Yi}+\mathrm{i}-\mathrm{Yi} ; \mathrm{Ki}=\Delta \mathrm{Yi} / \Delta \mathrm{Xi}(\mathrm{i}=1,2 \ldots ., \mathrm{n}-1)$. If $\mathrm{K} 1=\mathrm{K} 2=\ldots=\mathrm{Kn}-1 . \quad$ (3)

Then at point (Xi, Yi) position for example on a straight line: If Xi is constant, i.e. value of Xi are equally distributed, and then convinced enough that $\Delta \mathrm{Yi}$ is also constant (or almost constant).

During analysis and writing chemical laws and physio-chemical processes and phenomenon of empirical formula is common choose within the following functions (4-42):

$\mathrm{Y}=\mathrm{Ax}+\mathrm{B}($ Linear $)$

$\mathrm{Y}=\mathrm{AB}^{\mathrm{x}}($ Exponential);

$\mathrm{Y}=1 / \mathrm{Ax}=\mathrm{B}$ (Rotational);

$\mathrm{Y}=\mathrm{Aln} \mathrm{X}+\mathrm{B} \quad$ (Logarithmic);

$\mathrm{Y}=\mathrm{AX}^{\mathrm{B}} \quad$ (Exponential, which if $\mathrm{B}$ is $=0$, graph is parabolic and if $\mathrm{B}=0$, graph is Hyperbolic);(8)

$\mathrm{Y}=\mathrm{A}+\frac{B}{X}($ Hyperbolic);

$\mathrm{Y}=\frac{\mathrm{X}}{\mathrm{Ax}+\mathrm{B}}$ (Rational);

In order to define which of the function is better or suitable for the experimental data, it is necessary to perform the following operations:

$\mathrm{Xap}=\frac{x 1+x n}{2} \quad$ (average arithmetical $\mathrm{x}$ and $\left.\mathrm{y}\right)$

$\mathrm{X}_{1} \quad=0.01407 ; \mathrm{X}_{4}=0.02019$

Xap $=\frac{0.01407+0.02019}{2}=0.01713$ 
$\mathrm{Xreom}=\sqrt{x 1+x n}$ (average geometrical);

Xreom $=\sqrt{0.01407+0.02019}=0.0168$

$\mathrm{Xrapm}=\frac{2 x 1 . x n}{x 1+x n 2} \quad$ (average harmonic);

$\mathrm{Xrapm}=\frac{2 \times 0.0407 \times 0.02019}{0.0407+0.02019}=0.01658$

Yap $\quad=\frac{y i+y n}{2}$

Yap $\quad=\frac{y 1+y 4}{2}=\frac{126.499+71.26}{2}=98.879$

Yreom $=\sqrt{y 1 \times y n}=\sqrt{y 1 \times y 4}=\sqrt{126.499 \times 71.26}=94.9437$

Yrapm $=\frac{2 \times y 1 \times y n}{y 1 \times y n}=\frac{2 \times y 1 \times y 4}{y 1 \times y 4}=\frac{2 \times 126.499 \times 71.26}{126.499 \times 71.26}=91.1647$

$\mathrm{Y}^{*} \mathrm{ap}=Y i+\frac{y i+1-y i}{x i+1-x i}(\mathrm{Xap}-\mathrm{Xi})$

Where $\mathrm{Xi}, \mathrm{Xi}+1$-Given value among which falls within the range Xap $(\mathrm{Xi}<\mathrm{Xap}) ; \mathrm{Yi}<\mathrm{Y}^{*}<$

$\mathrm{Yi}+1(\mathrm{I}=1,2, \ldots \mathrm{n})$

$0.01713<$ Xap $<0.02919$, then 71.26 < Yap 91.16;

$\mathrm{Y}^{*} \mathrm{ap}=71.26=\frac{91.16-71.26}{0.02019-0.01710}(0.01713-0.01713)=71.26$

$0.01537<$ Xreom< 108.68 ;

$\mathrm{Y}^{*}$ roem $=91.16+\frac{71.26-91.16}{0.01713-0.01537}(0.01685-0.01537)=74.42$

$0.01407<$ Xrapm < 0.01537; $108.68<$ Yrapm < 126.499;

$\mathrm{Y}^{*}$ ap $=108.68+\frac{126.499-108.68}{0.01537-0.01407}(0.01658-0.01407)=143.08$

\subsection{Finding quantities using following equations}

$$
\begin{aligned}
& \epsilon_{1}=\mid Y^{*} \text { ap-Yap }\left|; \quad \epsilon_{1}=\right| 71.26-98.879 \mid=27.61 \\
& \epsilon_{2}=\mid Y^{*} \text { ap-Yreom }\left|; \quad \epsilon_{2}=\right| 71.26-94.94 \mid=23.68 \\
& \epsilon_{3}=\mid Y^{*} \text { ap-Yrapm }\left|; \quad \epsilon_{3}=\right| 71.26-91.164 \mid=19.90 \\
& \epsilon_{4}=\mid Y^{*} \text { reom-Yap }\left|; \quad \epsilon_{4}=\right| 143.08-98.879 \mid=44.20 \\
& \epsilon_{5}=\mid Y^{*} \text { reom-Yreom }\left|; \epsilon_{5}=\right| 74.42-94.94 \mid=20.52 \\
& \epsilon_{6}=\mid Y^{*} \text { rapm-Yap }\left|; \quad \epsilon_{6}=\right| 143.08-98.879 \mid=44.20 \\
& \left.\epsilon_{7}=\mid Y^{*} \text { rapm-Yrapm } \quad\right] \epsilon_{7}=|143.08-91.16|=51.92
\end{aligned}
$$

And define minimum value of $\epsilon=\min \left\{\epsilon_{1}, \epsilon_{2}-\epsilon_{7}\right\}$ 


\subsection{Select empirical formula among the function 1-7. Known empirical formula will have the following form:}

$Y=A x+B \quad$, if $€=\epsilon_{1}$;

2. $Y=A B^{x} \quad$, if $\epsilon=\epsilon_{2}$;

$Y=1 / A x=B \quad$,if $\epsilon=\epsilon_{3}$

$Y=A \ln x+B \quad$,if $€=\epsilon_{4}$

$\mathrm{Y}=\mathrm{AX}^{\mathrm{B}} \quad$,if $\epsilon=\epsilon_{5}$;

$\mathrm{Y}=\mathrm{A}+\frac{B}{X} \quad$,if $€=\epsilon_{6}$

$Y=\frac{X}{A x+B} \quad$,if $\epsilon=\epsilon_{7}$;

It follows that we must consider that functions 1-7 are monotonous, and therefore to answer them through experimental data $(\mathrm{Xi}, \mathrm{Yi})$ when $\Delta \mathrm{Xi}=\mathrm{Xi}+1-\mathrm{Xi}>0(\mathrm{I}=1,2, \ldots \mathrm{n}-1)$. We must have permanent sign. Alternatively, dependence 1-7 will be opposite. This method of choosing the type of empirical formula is a crude form, so far it does consider all the value of (Xi, Yi). Apart from that, it can happen that variables X and Y obey another law, and the type of empirical formula will be different from function $1-7$, so we choose function 3 , as it is $\min \left\{€=\epsilon_{3}=19.9\right\}$ and has form:

$\mathrm{Y}=\frac{1}{\mathrm{Ax}+\mathrm{B}} ; \quad \mathrm{q}=\frac{1}{0.9985 \mathrm{tTEX}-0.000006} ;$

The remaining equations were chosen in the same way. By the derived equations, tables and graphs were plotted. From them it is clear that the calculation by equations corresponded to the initial data of graph. While varying the continuity of refinery, dependence of working index of the furnace were as presented in Table 3.

Table 3 Effect of increasing continuity of refinery on productivity of furnace and relative usage of electric through smelting.

\begin{tabular}{|l|l|l|l|l|l|l|}
\hline $\mathbf{T}$ & $\mathbf{T}_{\text {texє }}$ & $\mathbf{I}_{\text {1ref }}$ & $\mathbf{W}_{\text {ref }}$ & $\mathbf{W}_{\boldsymbol{\epsilon}}$ & $\mathbf{Q}_{\text {ref }}$ & $\mathbf{Q}_{\boldsymbol{\epsilon}}$ \\
\hline Min & Hour/ton & A & mW-Hour/ton & mW-Hour/ton & ton/Hour & ton/Hour \\
\hline 20 & 0.01405 & 6.1497 & 0.0542 & 0.5463 & 253.0 & 71.15 \\
\hline 25 & 0.01536 & 33457 & 0.0662 & 0.5583 & 190.1 & 65.09 \\
\hline 35 & 0.01712 & 32293 & 0.0823 & 0.5744 & 142.5 & 58.42 \\
\hline 40 & 0.02018 & 31199 & 0.1103 & 0.6024 & 99.2 & 49.55 \\
\hline
\end{tabular}

$q^{\prime}$ tTex $=\frac{1}{0.99922 \text { tTEX }-0.0000157}$, ton $/$ Hour.

Calculate values received from those equations were presented in the Table 2.

Table 4 Effect of continuity of refinery on productivity of furnace and relative usage of electric throughout the smelting.

\begin{tabular}{|l|l|l|l|l|}
\hline T, Min & $\mathbf{2 0}$ & $\mathbf{2 5}$ & $\mathbf{3 5}$ & $\mathbf{4 0}$ \\
\hline $\mathrm{T}_{\mathrm{Tex}}$, Hour/ton & 0.01405 & 0.01536 & 0.01712 & 0.02018 \\
\hline $\mathrm{W}_{\epsilon}$ Mw-Hour/ton & 0.5406 & 0.5550 & 0.5744 & 0.6079 \\
\hline $\mathrm{q}_{\epsilon}$, ton/Hour & 71.15 & 65.09 & 58.40 & 49.59 \\
\hline
\end{tabular}

Usage by limit can be defined as follows: 
$\mathrm{Ct}_{\mathrm{TEX}}=\mathrm{n} / 0.99922 \mathrm{t}_{\mathrm{TEX}}+0.0000157=\mathrm{m} / 11 \mathrm{t}_{\mathrm{TEX}}+0.386+\mathrm{A}^{\prime}$

$\mathrm{Ct}_{\mathrm{TEX} \min }=1329.27 / 0.099922 \times 0.01405+0.0000157 /+13.58 / 11 \times 0.01405+0.386 /+14.938$

$=40.96$ Rouble $/$ ton .

$\mathrm{Ct}_{\mathrm{TEX} \max }=1329.27 / 0.099922 \times 0.02018+0.0000157 /+13.58 / 11 \times 0.02018+0.386 /+14.938$

$=50.02$ Rouble $/$ ton .

$\Delta \mathrm{Ct}_{\mathrm{TEX}}=\mathrm{Ct}_{\mathrm{TEX} \min }-\mathrm{Ct}_{\mathrm{TEX} \max }=50.02-40.96=9.06$ Rouble $/$ ton .

Calculated values of dependence of expenditure by limit were presented in Table 2 and on Figure 1.

Table 5 Effect of continuity of refinery on expenditure by limit.

\begin{tabular}{|l|l|l|l|l|}
\hline T, min & $\mathbf{2 0}$ & $\mathbf{2 5}$ & $\mathbf{3 5}$ & $\mathbf{4 0}$ \\
\hline $\mathrm{T}_{\mathrm{Texe}, \text { Hour/ton }}$ & 0.01405 & 0.01536 & 0.01712 & 0.02018 \\
\hline $\mathrm{Ct}_{\mathrm{TEX}, \text { Rouble/ton }}$ & 40.96 & 42.89 & 45.49 & 50.02 \\
\hline
\end{tabular}

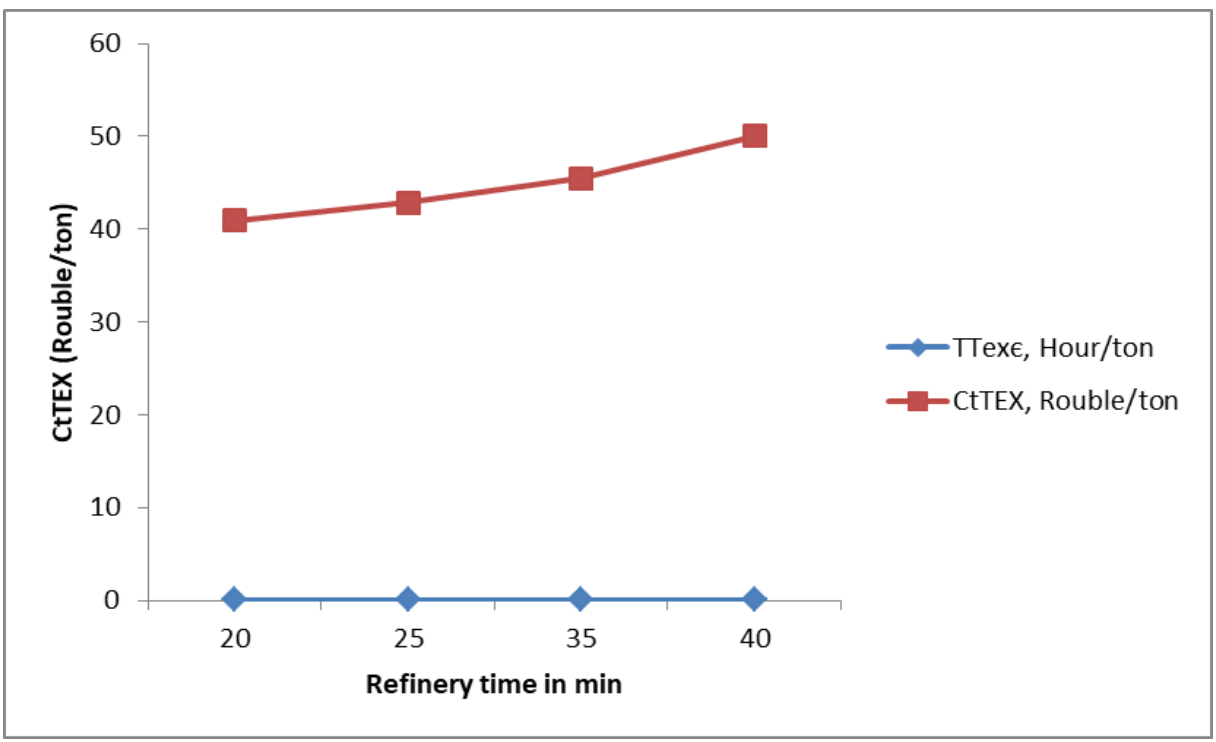

Figure 1 Plot of EAF expenditure versus refinery time in min.

\section{Discussion}

Similar results were obtained in past research where increase in refinery time increased cost of production and reduced productivity [11].

\section{Conclusion}

We can conclude that with increase in continuity of refinery, cost of expenditure by limit also increased. Within the checking limit Time rises from 20 to 40mins; increasing the continuity of the process of smelting within every 10 minutes, the cost limit increases by 4.53 Rouble/ton or by $11 \%$ thus productivity reduces. It can be concluded that increasing refinery continuity reduces working productivity of the electric arc furnace. 


\section{Compliance with ethical standards}

\section{Acknowledgments}

I wish to acknowledge the support given by Prof. Karacev V.P. during the working period

Disclosure of conflict of interest

There is no conflict of interest

\section{References}

[1] Muhlbaner A, VonStrack A, Kramer C. Handbook of thermo-processing technologies; Fundamental processes components safety. Essen Germany. Vulkan Verlag. 2005.

[2] Toulouevski, Y., Zinurov, I. Innovation in Electric Arc Furnaces. Verlag Berlin. Springer. 2010.

[3] Bowman B, Kruger K. Arc Furnace Physics. Dusseldorf. Verlag Stahleisen, 2009.

[4] Dittmer B. and Krüger K., "Theoretical approach to modeling thermal radiation in electric arc furnaces", ElectroHeat International, Vol. 4, (2009), pp. 195

[5] Beites LF, Maya R, Domo JG, Hemandes A, Asensi K. Harmonics interharmonic unbalanced of arc furnaces, a new frequency domain approach IEEE Transactions on power Delievery. 2001; 16(4): 661-66.

[6] International Energy Agency(IEA).World Energy outlook 2014. Paris. IEA publications, 2014.

[7] Logar V, Dovzan D, Skrjanc I. "Modeling and validation of an electric arc furnace: Part 1, heat and mass transfer" ISIJ Int. 2012; 52(3): 402-12.

[8] Logar V, Dovzan D, Skrjanc I. "Modeling and validation of an electric arc furnace: Part 2, thermo-chemistry"ISIJ Int. 2012; 52(3): 413-23.

[9] Logar V, Skrjanc I. "Modeling and validation of the radiative heat transfer in an electric arc furnace" ISIJ Int. 2012; 52(7): 1225-32.

[10] Morosov A.N. Modern production of steel in Arc Furnace, $2^{\text {nd }}$ Edition, Chelyabinsk. Metallurgy 1987.

[11] Okediran IK, Adetunji OR. Effect of Oxygen Usage on the Production Cost Optimization of Electric Arc Furnace; Journal of NiMechE. 2017; 7(1): 53-62. 